\title{
EL PEZ DE ORO, DE GAMALIEL CHURATA, EN LA TRADICIÓN DE LA LITERATURA PERUANA
}

\author{
HELENA USANDIZAGA
}

\begin{abstract}
Nadie vio en el mugriento español de Huamán Poma, o Tupak Khatari, la dialéctica de una estética; ningún crítico tabuló la chaskhadera; se la dejó para los espectáculos del Thantakhatu; jamás se pensó en extraerla de las zonas plebeyas a que el alma americana fue confinada ${ }^{1}$.
\end{abstract}

Este trabajo pretende ser una reflexión sobre la obra poco conocida de Gamaliel Churata (Arequipa, 1897-Lima, 1969), especialmente sobre El Pez de Oro (1957), que para algunos es «la Biblia del indigenismo $»^{2}$ y para otros «uno de los grandes retos no asumidos de la crítica peruana» ${ }^{3}$, si bien el reto se está asumiendo en los últimos años en una serie de trabajos críticos que mencionamos a lo largo de estas páginas. Para evaluar esta obra, hay que observar la evolución de Churata desde la época del Boletín Titikaka (1926-30), órgano difusor del movimiento Orkopata que él mismo dirige desde 1925, hasta la publicación de El Pez de Oro en 1957. Este movimiento ha sido objeto de varios estudios, el más completo de los cuales es el de Vich'; pero es necesario distinguir a partir de él la evolución de un proyecto literario que se plasma en $E l$ Pez de Oro y que gira sobre uno de los ejes más importantes de la literatura peruana, la heterogeneidad de sus materiales literarios ${ }^{5}$.

\section{El proyecto literario de Gamaliel Churata}

Nos centramos en el proyecto estético y literario de Gamaliel Churata, en el que un elemento fundamental es el de hacer comunicar e interactuar las diferentes zonas cul-

turales sin postular un idealizado mestizaje; esto implica la pregunta sobre la posibilidad de que un no-indígena pueda conocer estos mundos, lo que lo acerca a casos como el de Arguedas que, aunque catorce años más joven que Churata, no está tan lejano de él en algunas fechas de publicación: El pez de oro, la obra clave de Churata, aparece en 1957; Los ríos profundos, quizás la novela más representativa de Arguedas, es de 1958. Ambos mueren en 1969; Arguedas, después de haber publicado bastantes obras posteriores a Los ríos profundos; Churata, con varios inéditos y textos dispersos que se van recuperando gracias a estudiosos como Gonzales ${ }^{6}$ y Badini ${ }^{7}$. Churata no tiene el mismo tipo de contacto directo, de vivencia en los años de formación en el mundo indígena que Arguedas; pero su proyecto literario implica activar todo lo que conoce de este mundo.

Tengamos en cuenta que el propio $\mathrm{Chu}$ rata propone explícitamente sacar lo indígena y lo popular del lugar a donde fue confinado; entonces, explorar en el resultado que logra, sin hacernos caer en la tentación de desdibujar las jerarquías, nos permite ir más allá de las rígidas separaciones entre la cultura hegemónica y la subordinada en los Andes: cualquier entrada de la escritura en la cultura oral no se puede describir en términos sólo de apropiación, aunque apropiaciones las hay, y por

1

Gamaliel Churata, El Pez de Oro. Retablos del laykhakuy, La Paz / Cochabamaba, Canata, 1957 , p. 25
Omar Aramayo, El pez de oro, la biblia del indigenismo, Puno, Mimeo, 1979
Helena Usandizaga:

Es profesora titular de literatura hispanoamericana en la Universidad Autónoma de Barcelona. Sus líneas de investigación son la poesía peruana contemporánea y la literatura andina. Ha publicado numerosos artículos y capítulos de libro sobre estos temas, entre los que se destacan los dedicados a Moro, Eielson y Blanca Varela, por un lado, y a Arguedas y Gamaliel Churata, por otro. Es investigadora principal, desde 2003, de proyectos sobre la presencia de los mitos prehispáni$\cos$ en la literatura latinoamericana, financiados por el MEC; sobre este tema, como editora y coautora, ha publicado el libro La palabra recuperada. Mitos prehispánicos en la literatura hispanoamericana, Madrid / Frankfurt, Iberoamericana / Vervuert, 2006. Actualmente prepara la edición de El Pez de Oro, de Gamaliel Churata.

3

Antonio Cornejo Polar, La formación de la tradición literaria en el Perú, Lima, Centro de Estudios y Publicaciones, 1989, p. 140 nota. El reto se ha asumido en los últimos años con una cantidad considerable de trabajos que han abierto el debate sobre esta obra.

4

Cynthia Vich, Indigenismo de vanguardia en el Perú. Un estudio sobre el Boletín Titikaka Lima, Pontificia Universidad Católica del Perú, 2000.

5

Antonio Cornejo Polar, »El indigenismo y las literaturas heterogéneas: su doble estatuto socio-cultural», Revista de Crítica Literaria Latinoamericana (Lima), 7-8, (1978), pp. 7-21.

6

Guissela Gonzales Fernández, El dolor americano. Literatura y periodismo en Gamaliel Churata, Lima, Univesidad Nacional Mayor de San Marcos, 2009. Reúne los artículos de la época boliviana de Churata.

Riccardo Badini (ed.), Gamalie Churata, «El alfabeto del incognoscible», en preparación.
El pez de oro, de Gamaliel Churata, en la tradición de la literatura peruana

HELENA USANDIZAGA 
8

Churata, op. cit., p. 108.

9

Ibid., p. 90.

10

Vich, op. cit., p. 25.

11

Id.

12

Ibid., p. 25.

13

Humán, op. cit., p. 63.

14

Vich, op. cit., p. 28.

15

José Tamayo Herrera, Historia social e indigenismo en el altiplano, Lima, Ediciones Treintaitrés, 1982, p. 265.

16

Después de la inencontrable primera edición que reseñamos más arriba, se hizo una segunda que fue poco difundida, editada en Puno, Corpuno, 1987. Actualmente se está preparando una nueva edición: Helena Usandizaga, (ed.), El pez de oro. Retablos del laykhakuy, Madrid, Cátedra, en preparación.

17

Churata, op. cit., p. 7.

El pez de oro, de Gamaliel Churata, en la tradición de la literatura peruana

HELENA USANDIZAGA lo general la cultura hegemónica desconoce y deforma aquello de lo que se apropia, pero conviene ver aquellos casos en los que la interacción ilumina la relación entre ambas partes. Observemos también que el propio Churata, en su proyecto, no estratifica privilegiando el espacio de la escritura, puesto que en la cita que encabeza este trabajo no se habla de una literatura o cultura esencialmente «oral», «popular» o "plebeya», que estaría por debajo de la «culta», sino de una que fue catalogada como tal para marginarla; no hay tampoco en Churata un desprecio por un estrato supuestamente inferior, sino una protesta que tiene que ver con el encasillamiento y la incomunicabilidad de determinados modos culturales, a base de adjudicar connotaciones peyorativas a sus productos.

El Pez de Oro representa así un esfuerzo por construir una estética a partir de la cosmovisión andina en contacto con la cultura occidental de Churata; ambas culturas se manifiestan y se declaran en este proyecto como precarias y caóticas, pues el propio Churata reconoce que maneja mal las lenguas y la cultura nativas, como veremos al hablar de su proyecto lingüístico, y que su cultura occidental a veces le llega a través de recopilaciones divulgativas. Es cierto que tan pronto cita a Platón como a Goethe, a Einstein o a Marx, pero reconoce con una humildad no exenta de ironía que sus fuentes no son a veces directas: «En la mecánica del movimiento, enseña Bergson ( $\mathrm{y}$ al testimonio acudo de ese prodigioso Museum, de que yo y no pocos analfabetos nos abastecemos: The Reader Digest)...» ${ }^{\circledR}$; en otro momento cita como autoridad el almanaque Bristol' 9

Pero Churata usa con naturalidad sus referencias, que muchas veces parecen leídas directamente: sobre su formación cabe decir que la letrada es más bien autodidacta ${ }^{10}$, a partir de lecturas procesadas por un espíritu «iluminado» que es lo que significa Churata en aymara: clásicos griegos y romanos, San Agustín, Spinoza, Vives; más tarde, Whitman y Nietzsche, como explica Vich ${ }^{11}$, quien también señala su elección de quedarse en Puno como colaborador con el periodismo en vez de asistir, como la mayor parte de la intelectualidad sureña, a la Universidad de San Agustín de Arequipa ${ }^{12}$. La autóctona tiene seguramente que ver con determinadas lecturas que reivindica -Huamán Poma, Tupac Khatari, Garcilaso- y aquellas que detecta
Huamán ${ }^{13}$-por ejemplo, Dioses y hombres de Huarochirí, o su estela oral- y con el conocimiento de las comunidades nativas y de sus ritos, que debe de haberle comunicado algo de esa sabiduría. En este sentido, Vich ${ }^{14}$ cita a Tamayo Herrera para registrar que Churata y sus contertulios, en las reuniones que celebraban los sábados por la tarde hasta el anochecer (las llamadas «pascanas nocturnas») o los domingos durante el día, «bebían chicha y licor, picchaban coca, se ponían chullos, cantaban en quechua y aymara, leían libros en voz alta, se sahumaba la habitación con incienso y consumían picantes» ${ }^{15}$. Pero esta relación, que sugiere una especie de forzada representación teatral, como si se jugara a «ser indios», es chocante sólo por la enumeración: habría que confrontarla con las prácticas que realmente y con bastante naturalidad lleva a cabo la capa misti y mestiza especialmente en las zonas rurales de la región de Puno.

\section{El Pez de Oro en el contexto literario de Gamaliel Churata}

Churata escribió algunas narraciones y poemas y muchos artículos; los artículos de la época de La Paz acaban de recogerse en el antes mencionado libro de Gonzales Fernández. Su obra más importante, sin embargo, es El Pez de Oro, publicada como dijimos en 195716. Pues El Pez de Oro es un texto bastante más tardío que la época de Orkopata y el Boletín Titikaka, al parecer reescrito antes de su publicación en 1957, puesto que una edición anterior del texto comenzado hacia 1927, ya en la imprenta en 1930, habría sido destruida por un ataque fascista ${ }^{17}$. El texto tiene once secciones o capítulos, algunos divididos en subsecciones, la última de las cuales es «EL PEZ DE ORO», que no sólo repite el título sino también una sección anterior, si bien esta última se distingue tipográficamente por estar en mayúsculas. El discurso se formula sobre todo como narración, apelación, y a veces diatriba, de un enunciador que cambia su identidad (en varios pasajes es el propio Khori-Puma, uno de los seres míticos que pueblan la obra) y que se dirige a menudo a un enunciatario, también cambiante («amigo mío», «querida niña», «Capitán»...), quien a menudo interviene en el discurso que se convierte así en diálogo; en ocasiones uno de los dos se convierte en un narrador que se dirige a un hipotético lector. Los capítulos 
cambian pues de situación, lo cual a veces se señala con una línea de puntos. Por otro lado, la estructura básica del diálogo incluye diferentes tipos de texto: versículos numerados ${ }^{18}$, poemas de forma autóctona escritos casi siempre en un castellano híbrido, y a veces en quechua o en aymara, ensayos filosóficos o políticos, relatos sobre personajes de la historia de América desde la colonia, mitos o leyendas que corresponden o no a la materia tradicional, otros relatos de índole más realista, que a veces corresponden a la vida del enunciador. En el trasfondo de la obra juegan textos como los de Guamán Poma, el Diario de Colón, la Biblia, los clásicos españoles, las vidas de santos que leyó en Potosí, hechos relativamente contemporáneos como la matanza de Chicago en 1886, alusiones al imperialismo norteamericano... En esta estructura intervienen además otro tipo de textos como propuestas de leyes para los educadores ${ }^{19}$, o arengas del Inka ${ }^{20}$. Todo ello, como decíamos, trufado de citas prestigiosas usadas con cierta ironía. Por otro lado, los diálogos presentan a todo tipo de personajes: por ejemplo, hay un duelo verbal entre el Diablo, que es español, y el Khori-Puma, pero no termina con una victoria sino con la compasión del Khori Puma ${ }^{21}$. Desde luego, la propuesta de Huamán de vincularlo con el tinkuy, ritual indígena de lucha y encuentro, tiene sentido por la reunión de distintos géneros y por el tipo de relaciones que se establecen entre los contrarios; Huamán añade a éste otro modelo, el del pukllay o carnaval andino en todo su dialogismo y conflictividad, que conforma el tono cultural que define al texto en su totalidad. Lo más interesante es esta mezcla y la forma frecuentemente dialógica, polifónica, estructurada en forma de discusiones paradójicas a veces llevadas por un mismo sujeto desdoblado. Según Kaliman ${ }^{22}$, el hilo conductor es la utopía de restauración dinástica: el Pez de oro es sucesor del Puma de oro a quien Manco Capac encargó restaurar la dinastía antes de desaparecer en el lago Titicaca; esta vuelta del Khori-Challwa, paralela a la vuelta de Inkarrí en los mitos andinos postcoloniales, representa un pachacuti, una inversión catastrófica del mundo, pero también una restauración y una regeneración:

Cuando el lago arda, bramen volcanes, y el KhoriChallwa regrese de la tierra a la tierra, florecerá el corazón del mundo. ¡Estad atentos a un rugido que sacudirá las estructuras del Universo! ¡Temblaréis los vivos y se levantarán los muertos!23.

Pero este proceso no es sólo una reivindicación, sino una búsqueda estética y de conocimiento. Churata propone que América sea América a partir de esa integración en lo previo y lo profundo, lo cual no implica ni fatalismo ni retroceso, sino apertura:

Vivir en caverna, en la caverna y para la caverna, con el infracturable destino de la unidad vital, que no es más que el gozo de la fertilidad. Y como no se puede estar vivo y muerto, ni estar en dos naturalezas, ni objetiva y simultáneamente, estar en dos sitios, hay que estar en tensión lactéa, que el punto de tensión es el punto de la caverna $2^{24}$.

Esta obra, que se resiste a la clasificación genérica, busca en la caverna primordial la conexión con lo andino, y cabe preguntarse cuáles son los elementos de esta búsqueda. El contenido andino tradicional de la obra se ha discutido, pero en los últimos años se viene ya demostrando y trabajando ${ }^{25}$. Además de la hibridez lingüística y de las formas literarias, el texto intenta incorporar la sabiduría y el conocimiento andinos, canalizándolo sobre todo a través de los mitos y también de modos de conocimiento o articulación del mundo que se convierten en procesos discursivos: los modos cognoscitivos basados en la oposición y complementariedad de los contrarios que estudian los mencionados trabajos de Huamán y Bosshard, a través de conceptos como pachakuti, tinkuy, yanantin, taypi, kuti, así como el pukllay o carnaval andino al que aludimos en el trabajo de Huamán; el animismo; la sabiduría chamánica y sus modos peculiares de enunciación, en especial la estructura de la convocación ${ }^{26}$. Todo esto hace que el texto sea polifónico y dialógico, pues a menudo cambia el enunciador, quien, como decíamos, se dirige a diversos enunciatarios, incluido por supuesto el lector, de modo que el texto se estructura como una conversación que logra presentar los temas no como algo dado, sino como un saber que se construye en el texto mediante estos modos dialógicos y a menudo paradójicos. A través de estas formas, la preocupación de Churata no es tanto «representar»al indio como conectar con su saber, que, según apunta el autor, no se manifiesta debido a circunstancias históricas.
18 Ibid., p. 228

19 lbid., p. 484

20 lbid., p. 520

21 lbid., p. 172.

22

Ricardo Kaliman, «Literatura andina contemporánea». Curso dictado en el Centro de Estudios Andinos Bartolomé de las Casas. Cusco, Perú, agosto de 1996.

23

Churata, op. cit., p. 448.

24

Ibid., p. 45.

25

Ricardo Badini, «La ósmosis de Gamaliel Churata», Memorias de JALLA Tucumán 1995, vol. I, Tucumán, Proyecto «Tucumán en los Andes», pp. 344-351; Marco Thomas Bosshard, "Mito y mónada: la cosmovisión andina como base de la estética vanguardista de Gamaliel Chu rata», Revista Iberoamericana, 73: 220 (2007), pp. 515-540; Miguel Ángel Huamán, Fronteras de la escritura. Discurso y utopía en Churata, Lima, Horizonte, 1994; Manuel Pantigoso. El ultraorbicismo en el pensamiento de Gamaliel Churata, Lima, Universidad Ricardo Palma, 1999; Ulises Juan Zevallos Aguilar, Indigenismo y nación. Los retos a la representación de la subalternidad aymara y quechua en el Boletín Titikaka (1926-1930), Lima, Instituto Francés de Estudios Andinos, 2002.

26

Estudiada en Helena Usandizaga, "Cosmovisión y conocimiento andinos en $\mathrm{El} \mathrm{Pez}$ de Oro, de Gamaliel Churata», Revista andina, 40 (2005), pp. 237-259.

\footnotetext{
El pez de oro, de Gamaliel Churata, en la tradición de la literatura peruana

HELENA USANDIZAGA
} 
27

Huamán, op. cit., p. 32.

28

lbid., p. 66.

29

Churata, op. cit., p. 43

30

Pantigoso, op. cit., pp. 304-

330.

31

Khatarina Niemeyer, Subway de los sueños, alucinamiento, libro abierto. La novela vanguardista hispanoamericana, Madrid / Frankfurt, Iberoamericana / Vervuert, 2004.

32

Gonzales Fernández, Guisella, "Gamaliel Churata: una visión del indio y de Mariátegui», en Simposio Internacional "Amauta y su Época», Lima, Librería Editorial "Minerva», 1998. (247-253), p. 250.

33

Ibid., p. 252.

34

Op. cit., p. 251.

35

Vich, op. cit., p. 60.

36

Luis Emilio Valcárcel, Tempestad en los Andes, Lima, Universo, 1972.

37

Vich, op. cit., p. 92

38

Uriel García, «El nuevo indio», Amauta, 8, pp. $19-20$ y 25 (1927) p. 20, citado por Vich, op. cit., p. 98. El proyecto de Valcárcel y éste de García son quizás los que más peso tuvieron en el discurso peruano de la época.

El pez de oro, de Gamaliel Churata, en la tradición de la literatura peruana

HELENA USANDIZAGA
Por eso añadimos que el significado de los mitos, en la obra, no es el de una repetición del pasado, ni el de la prefiguración ineludible de algo por venir, sino el de la propuesta de un punto de partida que es a la vez sabiduría y goce, exploración en el futuro a partir de lo previo. Huamán detecta «una estrategia de lectura que nos permite acceder a otros niveles de análisis» ${ }^{27}$, es decir, un movimiento cognitivo, perceptivo y organizativo y no una representación de «lo otro» como en gran parte del indigenismo de la época. El Pez de Oro no es solamente un texto que marca una percepción andina, sino también, según Huamán ${ }^{28}$, un texto que dibuja un receptor andino: "Presiento que me leen Challwas», dice, citando a Churata ${ }^{29}$. La disposición del texto en retablos, señalada en el subtítulo de la obra y analizada por Huamán, o en movimientos inspirados en las constelaciones estudiados por Pantigoso ${ }^{30}$, corresponde al valor no lineal ni secuencial del texto, que se organiza así por la lectura de mitos, temas $\mathrm{y}$ motivos mediante diferentes estructuras y convenciones genéricas. Por otro lado, Niemeyer $^{31}$ ha señalado lo productivo de una lectura que tenga en cuenta también la trama del texto, basada sobre todo en la búsqueda que realiza el enunciador de sus raíces andinas y de una escritura que conecte con ellas y con la reivindicación de este mundo.

\section{El Pez de Oro en el contexto ideológico y estético de Churata}

Para entender hasta qué punto Churata es consciente de su inserción en el contexto cultural andino, antes de examinar su proyecto, hay que situar al Churata de El Pez de Oro en su época de maduración ideológica y estética, que coincide con su estancia en Potosí (Bolivia), donde se refugió por la persecución ideológica y artística de Sánchez Cerro, entre 1932 y 1964. En cuanto a lo ideológico, para Churata, el socialismo no es un descubrimiento de esta época, pero sí lo es la profundización en el marxismo y la ligazón con la reflexión estética, todo ello unido a un interés predominante, ya desde los años 20, por las ideas de Mariátegui, que le marcarían profundamente ${ }^{32}$. A partir también de Gonzales Fernández, quien opina que su preocupación por «lo americano» se hace en este momento más precisa y más ligada a lo indio como componente básico de lo americano o como lo americano mismo ${ }^{33}$, intuimos que su búsqueda es la de una estética capaz de expresar este mundo: en El Pez de Oro el indio no es un tema sino que se integra en la búsqueda de una forma y de una utopía que se alimentan de la tradición, ya que para Churata el quechua y el aymara son a ciertas civilizaciones americanas lo que el griego y el latín para las civilizaciones europeas. Por otro lado, Churata rechaza toda idealización en el planteamiento del problema indígena, y lo relaciona claramente con la desposesión y la injusticia, tal como señala Gonzales Fernández ${ }^{34}$, citando un fragmento de un artículo de 1937. Claro que las ideas de Churata no solucionarán la marginación del indio, pero el resultado de esta posición ideológica y estética queda plasmado en $E l$ Pez de Oro, como lo muestra el hecho de que Churata mismo haga una reflexión muy compleja y completa sobre el valor de lo andino en la literatura peruana, un valor que para él es fundamental. Este planteamiento, que se expone en el texto introductorio de $E l \mathrm{Pez}$ de Oro (1957) titulado «Homilía del Khori Challwa», sería comparable a los mucho más conocidos de Mariátegui, pero lógicamente más informado sobre la materia andina. Teniendo en cuenta la evolución de Churata y la inserción de El Pez de Oro en este contexto literario, ideológico y estético, examinaremos algunas de las diferencias con el proyecto del Boletín Titikaka.

\section{La visión del mestizaje}

En primer lugar, el mestizaje idealizado al que se refiere $V_{i c h}{ }^{35}$ como presente en declaraciones del Boletín Titikaka, propio de muchos discursos de la época, es releído por Churata, quien desde luego no propone, como Valcárcel ${ }^{36}$, una supuesta pureza o inmutabilidad del indio, el cual «habría persistido fuera del tiempo esperando su futura resurrección» ${ }^{37}$. Del mismo modo, sí percibe lo conflictivo y agónico de la heterogeneidad, al contrario de Uriel García, cuyo «neoindianismo», según Vich, es «una ondulación en la que se alternaba el influjo hispánico con el indígena en constante proceso de fusión» ${ }^{38}$. En El pez de oro, Churata es categórico al respecto:

Cualquier mestizaje es imposible, mas hay alguno impasable; y uno -bien se lo ve en este libro- es el del hispano y las lenguas aborígenes de la América, si 
en lo que llevamos de cultura cristiana, y lo mismo es decir española, hemos originado hasta el deleitoso y pecador connubio de Juan de la Cruz y Verlaine; mas hay infarto estético en que podamos decir: he aquí el connubio indo-hispano ${ }^{39}$.

Habría que matizar por lo tanto las afirmaciones que se basan en textos del Boletín Tititkaka y hacerlo señalando las diferencias con El Pez de Oro; Vich afirma, comentando «Indoamericanismo» (1928), un texto de Churata en esta revista, que

por medio de este tipo de pronunciamientos, Churata aboga por la facilidad que tienen los latinoamericanos para articular sus propias tradiciones con otras que vienen de fuera; para ser cosmopolitas sin dejar de ser regionales a la vez. La idealización de la categoría de mestizaje (entendida como una fusión positiva sin conflicto alguno) salta a la vista ${ }^{40}$.

Leyendo El Pez de Oro, por el contrario, se aprecia que Churata sale al paso de muchas ideas de la época, y aun sostenidas muchos años después, sobre el mestizaje: ni siquiera el racial le parece inocente, pues en él se manifiesta la desigualdad de la unión, y también el cultural lo analiza destruyendo tópicos, como el supuesto mestizaje armónico de Garcilaso, ya que detecta en él «la evidente subalternidad de lo indio» ${ }^{41}$. Del mismo modo, rechaza la celebración de la síntesis donde se ha impuesto la jerarquía, como en el supuesto valor mestizo del barroco, por ejemplo en las iglesias de Pomata y Juli, que sin duda Churata tuvo ocasión de contemplar largamente: «Los símbolos del Sol y de la Luna en las ideografías del plateresco colonial no han sido impuestas por el indio, ni admitidas con valor categorial por la Iglesia; son tan subsidiarias que sólo pueden obedecer a una concesión dentro del proceso catequista» ${ }^{42}$. La propuesta de Churata, es cierto, cabe interpretarla como una estrategia antes que como una definición definitiva:

No se vea en nuestra actitud fobia alguna contra España; la admiración que cultivamos por su genio, por el genio de sus grandes hijos, como -y más- por los españoles chicos de la gleba, nos cura de odiosidades de espantapájaros. Pueda que en el fondo nos inspiren odio sus hechos; pero el odio no destruye sino a quien le cultiva. Estamos, como hombres, frente a la negación de nuestra naturaleza que ella representa y supone; y sabemos que la manera de cancelarla en nosotros es volviendo por el régimen de la salud celular ${ }^{43}$.

El rechazo de lo español que propone Churata parece más bien una manera de acceder a lo propio que un rechazo definitivo de lo otro porque, de manera más consciente que Arguedas, Churata reivindica una corriente autóctona oculta pero viva, una corriente que se manifiesta también en la escritura. Al mismo tiempo, aparte de su vocación cervantina, conecta con lo más auténtico y desgarrado de la literatura española (Calderón, Santa Teresa de Jesús...). Como decíamos, Churata propone rescatar «lo popular» para la literatura culta, y no exactamente hablar de lo popular desde lo culto. Por otro lado, en la exposición que hace de las relaciones entre lo andino y lo español, muestra una perspectiva muy poco idealizante del mestizaje, como señalábamos anteriormente, y una conciencia clara de la subalternidad de lo andino respecto a lo español, así como de la importancia de la conservación de la percepción andina en determinados sujetos coloniales (Huamán Poma es para él un ejemplo, al contrario de Garcilaso) y del contagio de la percepción andina a los españoles. Aunque Churata a veces habla en términos de lengua, es evidente que su perspectiva es mucho más amplia; es cultural, y por lo tanto perceptiva y estética:

La verdadera capacidad estética de la América está en la sangre del indio y, por tanto, la forma de hacer estética americana es hacer de América un mundo indio; que será indio siempre, si la genésica de la cultura la suministra el habitante en cuanto naturaleza y fruto ${ }^{44}$.

Sin embargo, hay que repetir que lo estético no se separa del sentido, ni aun de lo ideológico y de lo ético. El aspecto de resistencia de la propuesta de Churata lo subraya Huamán; aquí querría solamente observar que se podría hablar de una identificación genésica con el espíritu de la raza y con la tierra; pero que para Churata la tierra, gracias al mito, no anula la historia, lo cual me parece de una importancia fundamental, porque las palabras del primer capítulo de El pez de oro contradicen de nuevo la perspectiva del mestizaje y la supuesta «visión biológica» de Churata:

El mito griego es el alma mater del mundo occidental; el mito inkásico debe serlo de una América del

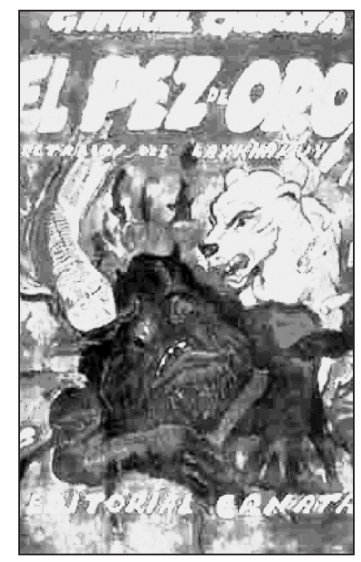

Portada de la primera edición de El pez de oro. Retablos del Laykhakuy de Gamaliel Churata (1957).

39

Churata, op. cit., p. 533.

40

Vich, op. cit., p. 60

41

lbid., p. 14.

42

Ibid., p. 42.

43

lbid., p. 533.

44

lbid., p. 17. \begin{tabular}{c}
$\begin{array}{c}\text { El pez de oro, de Gamaliel Churata, } \\
\text { en la tradición de la literatura } \\
\text { peruana }\end{array}$ \\
\hline HELENA USANDIZAGA
\end{tabular} 


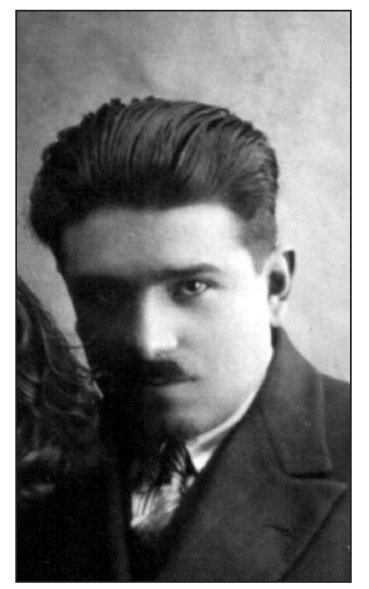

Arturo Peralta, Gamaliel Churata, en la época de Puno.

45
lbid., p. 33.
46
Vich, op. cit., pp. $59-60$.
47
Churata, op. cit., pp. $84-99$,
362.
48
Ibid., p. 84.
49
lbid., p. 86.
50
lbid., p. 40.
51
ld.
52
Vich, op. cit., pp. $127-128$.
53
Churata, op. cit., p. 16.
54
Las últimas citas corresponden
todas a ibid., p. 25.
55
Vich, op. cit., pp. 190-191

El pez de oro, de Gamaliel Churata, en la tradición de la literatura peruana

HELENA USANDIZAGA
Sur con «ego». Ciertamente, en la del Norte, frente al monstruoso poderío neobritánico, no es hispana la guardia de la frontera: es azteca. Deber de quienes detentan la Wiphala del Inka es no abandonar la batalla antes de la Victoria ${ }^{45}$.

\section{La visión genérica en $\mathrm{El} \mathrm{Pez} \mathrm{de} \mathrm{Oro}$}

Del mismo modo, la visión genérica en este trabajo más tardío se aleja del «criterio valorativo falocéntrico» que detecta $\mathrm{Vich}^{46}$ comentando «Indoamericanismo» (1928), texto aparecido en el número 22 del Boletín Titikaka. En el texto que cita Vich hay, en efecto, una oposición entre lo materno y lo varonil que se corresponde con la oposición germen/ plenitud y que, así leída, puede calificarse de falocéntrica. En cuanto a El Pez de Oro, hay en esta obra una complicada doctrina sobre los roles sexuales y sobre la fecundación/ germinación, así como sobre la paternidad/ maternidad y su relación con el erotismo, el amor y el dolor ${ }^{47}$; que es desconcertante lo muestra la referencia a las parejas varón/varona ${ }^{48}$, doncella/doncello ${ }^{49}$. Pero, a falta de espacio para entrar en este tema, baste señalar que el valor de lo materno es bastante diferente en El Pez de Oro; esto es especialmente evidente en uno de los mitos que cohesionan la obra, el de la germinación materna ligada al mito de la Pachamama. Aunque, si bien este mito refiere la ligazón del hombre con lo sagrado, ligada a la estética que se origina en lo primordial, y se opone a una serie de arquetipos de lo femenino, no deja de establecer una polaridad hombre/ mujer que adjudica roles aparentemente no intercambiables:

Tenemos palingenesia, indudablemente.

A la mundolatría que prende por acción oceánica en sus grupos artísticos, el desasimiento hoy cardinales, seguirá un arte de génesis, de lujuria y afincamiento en la patria láctea; pues allí se verá que la patria láctea no puede ser suprimida y todo lo que se hizo fue obligarla a permanecer en acecho, encrucijada y zozobra. El artista sentirá la voluntad creadora de una mujer genésica (sobrevendrá especie de matriarcalismo mental)...50.

Se propone así una vuelta a la «patria láctea» que comporta un «matriarcalismo mental» ${ }^{51}$; de tal modo que el papel preponderante lo tiene el elemento femenino. Esta presencia de lo femenino produce un ritmo corporal y de sensibilidad, lo cual supone una estética que se origina en lo primordial.

\section{El proyecto lingüístico de Churata}

El lenguaje churatiano de la época del Boletín Titikaka se ha visto como un vanguardismo sólo superficial, ejemplificado en Versos del achachila, aparecido en el Boletín Titikaka ${ }^{52}$. Comparando este texto aislado con la totalidad de El Pez de Oro, podemos observar en esta obra un vanguardismo que tiene que ver sobre todo con la ya comentada estructura y composición de la obra. Como veremos, el de Churata es en efecto un lenguaje desarticulado, en el que se mezclan el español y las lenguas autóctonas en un intento repetido de desaprender lo aprendido para buscar una nueva expresión que conecte con la cultura andina; en este sentido, Churata busca su propia tradición en textos ligados a lo andino. A este rescate, a esta reivindicación del lenguaje de por ejemplo Guamán Poma ${ }^{53}$, que podría llevar al uso del aymara y el quechua, se opone algo que sí se rechaza de modo categórico, y que es la retórica española, «lo que no soltamos del legado hispánico: la trónica, que truena con más vaciedad ahora que España nos falta con el humanismo de Vitoria, el genio de Calderón, el romanticismo quijotesco del padre Las Casas». No ha habido independencia («De la España española, sí. No de sus porquerizos») en cuanto a lo más negativo de lo cultural: «Seguimos españoles en el sentido obsceno de la españolidad; esto es en madrileñismo curialesco (sostenerlo no infiere fosca alguna por la nobiliaria de los Madriles) o sea en "pizarrismo» híspido, bravucón y dipsómano» ${ }^{54}$.

Se percibe aquí la mencionada estrategia de Churata, contraria al mestizaje, para llegar a lo propio. Del mismo modo, Churata parece en esta obra mucho más consciente de las posibilidades y limitaciones del uso de las lenguas vernáculas en la literatura, separándose de la consideración, por parte del Boletín, del «español como la única lengua posible en el campo de la cultura letrada» ${ }^{55}$. Churata es en él más realista y más crítico puesto que, al lado del español andino que le inspira Huamán Poma, percibe otras dos posibilidades que parece dejar abiertas, pero que no emprende por diferentes razones. Después de reconocer que no hay todavía literatura americana, que ésta es aún española, Churata señala que: 
«En tal punto el alud volcánico se dirige a la posibilidad Garcilaso, la posibilidad Huamán Poma o la posibilidad «Ollantay»». Es decir, una lengua hispanizante, una lengua híbrida o las lenguas autóctonas. «Si Huamán nos da el diapasón, nada tenemos que acometer que no sea jerarquizar el español híbrido que hablan nuestros pueblos, si lo tercero...» ${ }^{56}$, añade Churata; pues, en efecto, parece que se inclina por esta solución híbrida, pero no porque la tenga por definitiva, sino por adaptarla a sus posibilidades lingüísticas reales, en lo que se refiere al uso de las lenguas autóctonas, y porque considera que ya no es el momento de explorar en lo más hispánico (piensa además Churata $^{57}$ que lo mestizo desemboca en la «quejumbre», y critica ${ }^{58}$ al indio que se «cholifica»). La primera solución se rechaza entonces así, puesto que además la «trónica» española anteriormente mencionada constituye uno de los mayores obstáculos para llegar a una literatura americana. Parece entenderse, entonces, que a la larga una opción sería el uso del aymara y el quechua: «Una posibilidad de literatura americana quedaría resuelta (se entiende que para el área del Tawantinsuyu) si los escritores americanos pudiesen emplear el aymara y el kheswa» ${ }^{59}$. Es, por lo tanto, una imposibilidad real y momentánea la que ve Churata para el uso de las lenguas autóctonas, pero vislumbra la posibilidad de que se llegue a ello en el futuro: «El español tendrá que hibridarse rendiendo parias a Huamán Poma, o romperemos los «atajamientos» de Garcilaso, volviendo al aymara y al kheswa. Sólo entonces el punto de partida de "Ollantay» habrá encontrado continuidad. $\mathrm{Y}$ ya podremos hablar de Literatura Americana» ${ }^{60}$. Si bien es cierto que la lengua de Churata hay que tomarla como un ensayo, qué duda cabe de que se trata de algo original y valioso en tanto que expresión de este lugar fronterizo que es su literatura. Tomamos uno de los múltiples ejemplos de ese lenguaje:

Elake, Khori-Challwa, que en estas kellkas se trata de tu patria de oro y se llora en trinos la patria de tu trino. Se llora el trino de los huesos, del lakato, las thayas y del phesko. El agua gorgorea con gorjeos. Aúlla el perro lobo por sus trinos. Trina la kharka que te ama. La ahayu ya no trina porque te habla. Trina, llora y espera el Chullpa-tullu. El hombre de cabeza de llamo trina con tus trinos. Llamarada de trinos, el Khori-Puma, que con alada garra fue a despertarte del sueño en tu adormida estrella. Wirakhocha en su gloria de trinos y de oros, es ya sólo un trino de tu oro. Trina el monte, trina el aire, trina el agua. Trina en la Khellka la Imilla que por trinarte vino y ya es la pirwa de tus trinos. Trina la Pacha-Mama y es su corazón el nido de tus trinos. Tus trinos son, no hemorragia de mis llagas, Khori-Challwa. Trinos para el niño viejo, trinos para el viejo niño. Y los mismos alaridos del chullpar que espantan a los chiñis, son el trino de oro que trina con tus trinos ${ }^{61}$.

Este lenguaje híbrido parte de un español arcaico inspirado seguramente en sus lecturas de los clásicos, para mezclarlo con términos en quechua y aymara, términos que incluye en principio en un guión lexicográfico al final, guión que en realidad constituye más bien un diccionario personal. El castellano, a pesar de cierto descuido, está usado con pericia de diferentes maneras: a veces es un castellano "plebeyo» ${ }^{62}$, pero las más de las veces está elaborado de modos diversos, ya sea con el lenguaje filosófico ${ }^{63}$, ya con juegos de palabras ( Que la Muerte y Putifar tienen la suerte del badajo, mi docto Renacuajo, si bajo el barajo caen de tu atajo: ampollas, o bambollas, o centollas» $\left.{ }^{64}\right)$. Hay otros ecos intertextuales que cabría investigar: bequerianos («Entonces comprendí porque se muerde» ${ }^{65}$ ); o conectados con el discurso modernista y postmodernista, tal vez egurenianos, lugonianos o valleinclanescos («Mama-Khilla, clorótico fanal de todo drama de Ultratumba, a la sombra de sus ojeras volcaba lunáticos albayaldes en el montón de arrugas viejas de la tierra, donde, Duendes sin ellas, complotaban la fuga» $\left.{ }^{66}\right)$. La intertextualidad es profusa, con segmentos de la tradición occidental tan dispares como Walt Whitman o los versos al alma de Adriano. Pero, por otro lado, el texto se propone como algo ciertamente estimulante para un lector occidental, quien no puede apoyarse para descifrarlo en las referencias andinas, que no conoce, y que tampoco puede basarse sólo en el código vanguardista para entenderlo.

\section{La visión de lo indígena como universo cultural}

A partir de esas diferencias con lo más ingenuo del Boletín Titikaka hay que buscar la originalidad de esa obra de Churata, y evitar uniformizarlo a priori con los estereotipos que generan afirmaciones autoritarias y que muestran el desconocimiento y la idealización

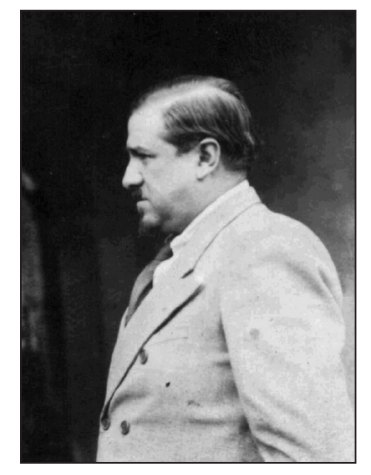

Gamaliel Churata en Bolivia. Fotos: cortesía de Pedro Pineda Aragón y de José Luis Velásquez Garambel

56

Churata, op. cit., p. 22.

57 Ibid., p. 18.

58

lbid., pág. 34 .

59

Ibid., p. 25.

60

Ibid., p. 26.

61

Ibid., p. 45.

62

Ibid., p. 170.

63

Ibid., p. 379.

64

Ibid., p. 363.

65

Ibid., p. 375 .

66

lbid., p. 288
El pez de oro, de Gamaliel Churata en la tradición de la literatura peruana

HELENA USANDIZAGA 
67

Vich, op. cit., pp. 176-184.

68

Ibid., p. 177.

69

Ibid., p. 179

70

Ibid., p. 179

71

Id.

72

Churata, op. cit., p. 237.

73

Ibid., p. 17.

74

Ibid., pp. 17-18.
El pez de oro, de Gamaliel Churata, en la tradición de la literatura peruana

HELENA USANDIZAGA de mundo indígena, plasmados en un actitud paternalista. Vich ${ }^{67}$, por ejemplo, comenta el proyecto educativo del poeta y profesor Emilio Vásquez, componente de Orkopata, y detecta la afirmación, en la base de este proyecto, de las capacidades intelectuales limitadas de los indígenas, «a los que siempre se les ubica en un nivel inferior, instintivo, completamente sub-desarrollado» ${ }^{6}$, opiniones que se sustentan en el concepto caduco y poco operativo de la oposición «civilización/barbarie» ${ }^{69}$. A partir de lo que dice Gonzales Fernández en su estudio sobre los artículos que escribió en la época de Potosí, en el mencionado contexto ideológico de Churata, a partir de los años 30, observamos algo diferente: cuando Churata habla de la educación, propone un modelo en el que el indio no tiene que ofrecer folklore a cambio de un regalo paternalista que no lo sacaría de su servidumbre; la educación que él defiende ha de desarrollarse en el ámbito del indígena, para salvarlo en su cultura y permitirle que busque su propio progreso. Churata es aún más claro en El Pez de Oro, y en estas afirmaciones y en otras que comentaremos a continuación, se diría que polemiza con su propio contexto de los años 20-30.

En este contexto, $\mathrm{Vich}^{70}$ contrapone a las afirmaciones paternalistas aquellas que explican las acusaciones de alcoholismo y adicción a la coca como modos de discriminación del indígena; pero la posición de Churata muestra algo que va más allá, un conocimiento cultural que no aparece en esa polémica. El rechazo por parte de Vázquez de «los vicios orgánicos de la raza» ${ }^{71}$, es decir, el alcohol y la coca, contrasta con el conocimiento de Churata del valor sagrado y cultural de la coca: podemos relacionar el conocimiento de lo sagrado andino que se deriva de esto con su oposición a ciertos tópicos del discurso indigenista más común en la época; en uno de los diálogos de la obra, el enunciador polemiza con la idea de que la coca estupidiza, y muestra que conoce bien sus efectos y simbología:

En innumerables hechos como éste me fundo para creer que ni el valor nutritivo de la coca, ni el espíritu del pueblo indio, han sido comprendidos. De la coca, afirman, y tú entre otros, ha bestializado al indio, que integra un hato de bestias... Soberbias orejas, doctor Fausto... Pachakutek, que cobra fama con Lloke Yupanki, si la memoria no me engaña, de uno de los más kukanis de los Inkas ("gran mascador de coca»), dice el Cronista), fue tan sabio como Licurgo, tan filósofo como Marco Aurelio, tan sensitivo como Adriano, y conquistador digno de hombrearse a Filipo o Ciro. Caben en un puño sus máximas; pero la experiencia de los hombres que ellas acusan, ya no. ¿Si la kuka hace posible tal iluminación psicofísica, cómo puede embrutecer? El auki en el ámbito de su mundo tiene mayestática de Loja; y su agudez inspira la certidumbre de que los mestizos podremos penetrar en la interna sabiduría de su palabra sólo cuando valores, internos también, nos confieran la aptitud necesaria para insumirnos en su profundidad. Eso es cultura y sólo eso patria ${ }^{72}$.

En relación con su valoración antropológica y no únicamente telúrica de lo indígena, Churata reclama para los indios la capacidad de generar cualquier producto cultural; si esto no se ha hecho efectivo, se debe a su condición de oprimidos, no a su inferioridad:

Si no conciliamos las prerrogativas del criollo con las mayores del indio, y de éste creemos que sirve para más que menestral, covachuela, portero de hotel, pillastre electoralero, alcahuetista, mientras para aquél reservamos los dones de la arcangelidad, nunca tendremos un poeta indio, como en cuatrocientos años no hemos metido un santo cuprífero a las hornacinas ortodoxas, que no se escatimaron para negros ni amarillos. El indio no es un subhumano, si ya sabemos que las imbecilidades de Sepúlveda fueron aniquiladas en su mismo vitriolo; es sí un subnutrido a causa de los sobrenutridos que lo apalearon y lo apaleamos todavía en prosa y en verso ${ }^{73}$.

Además, Churata se muestra consciente de los intereses que entran en juego cuando se decreta la inferioridad del indio:

El gran poeta «indio», que es don Franz Tamayo, decreta que de él se haga artesano, mecánico, tal vez práctico en ingeniería. Mas no, ni se procure, filósofo o esteta, que todo lo que ve con las elaboraciones de la imaginación le está negado. Realmente, por mucho que se medite en tesis tan insólita se penetra en sus razones. ¿Es que el indio es un animal detenido en las subestructuras de la volición instintiva? ¿Por qué constituiría ese estrato inmoble, si todos los pueblos, y los más típicamente manuales, como el sajón, han sido fecundos en poetas y filósofos? Dígase que más útil es en pongo y se comprenderá quién lo dice ${ }^{74}$.

Churata no es crítico únicamente con la opresión española, sino que se muestra muy consciente de fracaso que supone la independencia para la liberación del indígena: 
Hay, sin embargo, monstruosidad mayor. Es la legislación que se dan las «republiquetas» hispanoamericanas, pantográfico remedo y secuela de la Revolución Burguesa, con sustantivo y clamoroso desconocimiento de las "Leyes de Indias", que aunque fuese solo teóricamente y para negarlo, comprendían el problema del SER americano, son vestigio de reconocimiento de sus texturas ${ }^{75}$.

Esta exploración en lo andino se plantea como decíamos a partir de la vuelta a la célula, a la caverna; pero no se trata de una vuelta a los orígenes que ignoraría la historia, sino de volver al pasado a través del Khori-Challwa, el pez del origen, para encontrar la manera de situarse en el presente y en el futuro. Muchos de los elementos andinos que Churata mezcla con los occidentales tienen que ver con la idea de la búsqueda en el pasado; pero no como un eco spengleriano que también se le ha atribuido. Churata pudo acercarse a esta concepción «biológica», según un esquema positivista que asemejaría la historia de América al desarrollo del ciclo vital del ser humano ${ }^{76}$ en la época del Boletín Titikaka, pero leyendo El Pez de Oro se hace evidente que se sitúa ahora más allá del tópico de la joven América frente a la vieja y caduca Europa. En efecto, su concepción del tiempo es más mítica que biológica, pero no a la manera cíclica repetitiva con que se simplifican las visiones prehispánicas, sino en esta especie de ciclicidad en espiral que habría que explorar más en culturas como la maya o la andina.

Justamente en esta encrucijada temporal la perspectiva de Churata incorpora la visión andina del mundo de los muertos como lugar de génesis y de fecundidad para los vivos ${ }^{77}$. En cuanto a la idea de los muertos como semilla, lo relaciona con figuras míticas, y con el concepto de chullpa, que Churata define como sepulcro, mientras que el chullpar es el cementerio y el chullpa-tullu es «el esqueleto, mas el esqueleto vivo»; hay también referencia a El Chullpa, «americano legendario de edades presolares» ${ }^{78}$. El pasado ha de ser el pasado indígena, porque se busca la permanencia de un proyecto histórico específico: en un típico procedimiento churatiano, imagina que el maestro Eckardt pregunta al indio, quien le responde que en los indios muertos busca a los vivos, y en los indios antiguos a los nuevos. No se trata entonces de una temporalidad biológica, sino de una tempo-espacialidad mítica que, decíamos, no reproduce el ciclo vital humano: señala al pasado pero no como "vuelta al origen», sino como espacio de exploración y lucha para controlar el futuro. No en vano Churata hace una referencia al concepto marxista de la historia y la relaciona con esta visión mítica del pasado:

«¿Cuál la Abracadabra? En los indios de hoy deben estar los indios de ayer; o estos indios no son indios. Ya que sólo está el que estuvo, o el que está, y se dice, no es... Nada será sin estar. El «los muertos mandan» de Karl Marx, sonaba a paradoja para quienes no observan que el Materialismo Histórico debe ser mosaico en lo fundamental, por tanto secuela de mesianismo profético. ¿Pero, Marx entendía que los muertos mandan por que los muertos no son los vivos? En ese caso su pleroma búdico no poco y hasta tomista. Mas su paradoja se concreta ahora, puesto que podemos decir, sin anfibologías, sólo tiene autoridad el que ha muerto (por eso puede mandar) y autoridad de sabio aquél que sabe que el muerto es él 79 .

Estas concepciones de tiempo y espacio están muy a menudo ligadas a figuras míticas más concretas, por ejemplo el «mito temporario» de la isla del Waksallu, que formula la sensación que el Runahakhe obtenía del devenir: el Achachila, o Jefe arcaico, «incrustado en chinkhanas, manantiales, lagos, o kharkhas» no es así mera presencia nostálgica del ancestro. Del mismo modo, los chullpares no son meras necrópolis, sino «altares necrolátricos, donde adquiere el hombre conciencia de estancia y de raíz». En estos muertos reside el «Pasado no yerto, fértil; no detenido, fluyente» ${ }^{80}$. Por eso para Churata el lugar de los muertos es el lugar de la semilla; la lección de los chullpares es la de la vida y la inmortalidad:

En el corazón de los chullpares está el imperio de la sangre y se percibe su inmortalidad. Bulle con torrentes ardorosos, habla con la lengua de todos nuestros muertos, se agita con sus vidas, duele con los sueños, reclama sus derechos; de allí afloran para brindarnos el beso de la fraternidad que no se trunca, para avivar la hornalla que arde sin principio ${ }^{81}$.

De este modo se explica que la relación entre la vida y la muerte sólo puede producir más vida, pues la semilla debe arder para germinar, y la semilla son los antepasados, los muertos: " $i$ Tata-Lupi: ya arden los chullpares!»82 Ese incendio, entonces, es del sujeto y del universo y la percepción andina -la coca y
Vich, op. cit., p. 59.

77

Tal como señala Badini (op. cit., p. 348), lo que sin duda está en Churata es este impulso del pasado, del mundo de los muertos, estudiado por Bouysse-Cassagne y Harris, hacia el futuro: "La próxima edad brotará de donde salen los poderes repentinos e inciertos que nos dan vida y así los antepasados, la gente de tiempos anteriores, no sólo hacen fecundar la tierra desde el Manqha Pacha, sino que además son fuente de un futuro más lejano». Thérese BouysseCassagne y Olivia Harris, "Pacha: en torno al pensamiento aymara», en Tres reflexiones sobre el pensamiento andino. La Paz: Hisbol, 1987, (pp. 1159), p. 56.

78

Churata, op. cit., p. 540.

79

Ibid., p. 121

80

Todas las citas del párrafo corresponden a ibid., p. 122.

81

lbid., p. 97.

82

lbid., p. 81.
El pez de oro, de Gamaliel Churata, en la tradición de la literatura peruana

HELENA USANDIZAGA 
Francisco de Ávila, Ritos y tradiciones de Huarochirí. Manuscrito quechua de comienzos del siglo XVII, Gerald Taylor (ed.) Lima, Instituto de Estudios Peruanos/Instituto Francés de Estudios Andinos, 1987.

87

Efraín Morote Best, Aldeas sumergidas: cultura popular y sociedad en los Andes, Cusco, Centro de Estudios Andinos «Bartolomé de las Casas», 1988.

88

Millones, Luis y Tomoeda, Hiroyasu, "Las sirenas de Sarhua», Letras, LXXV: 107-108 (2004), p. 107.

\section{9}

Alberto Flores Galindo, Buscando un Inca, La Habana, Casa de las Américas, 1986.

90

Usandizaga, op. cit.

91

En este valor semántico del mito hay que observar un aspecto especialmente interesante: si bien el relato se puede sólo parcialmente asimilar con unidades narrativas de la tradición andina (transcritas en el momento de la colonia o transmitidas oralmente), el relato «inventado» por Churata funciona siempre utilizando elementos estructurales de la cosmovisión mítica andina tal como podemos reconstruir a partir de los testimonios antiguos, de la tradición oral y de prácticas rituales actuales.

92

Churata, op. cit., p. 64.

93

Ibid., p. 108.

94

lbid., p. 93.

\footnotetext{
El pez de oro, de Gamaliel Churata, en la tradición de la literatura peruana

HELENA USANDIZAGA
}

el Tawantinsuyu, o sea, el imperio inca- llevan a la acción: «Repugno de los tibios de corazón $\mathrm{y}$ de los tibios de voluntad» ${ }^{83}$.

Como vemos, la obra se estructura en torno a referencias míticas: la historia del Pez de oro o Khori-Challwa está construida literariamente a partir de historias encajadas en la principal o sólo aludidas, pero resulta sorprendente explorar en la materia mítica quechua y aymara, porque encontramos coincidencias, sobre todo en el sentido global de los mitos: El mito que subyace a todo el libro es en efecto el del Pez de Oro; se trata del relato del nacimiento de este hijo mítico engendrado por la unión del Khori-Puma con una sirena del lago Titikaka, tras una serie de búsquedas y pruebas que incluyen episodios de canibalismo (tal vez simbólicos, porque el Khori-Puma devora a la Sirena y al Khori-Challwa, hijo de ambos, aún antes de la secuencia en que se describe su nacimiento, tal como recalca Bosshard ${ }^{84}$ ), y que acompañan el cambio de era que supone la caída del «Lodo ardiente ${ }^{85}$. Me parece que en esta historia podemos hallar las huellas de mitos andinos como la lucha de Huallallo Carhuincho, el devorador de niños, con Pariacaca (el dios que habita dentro de un huevo, del que nacerá posteriormente); el episodio de las aguas y el fuego que caen sobre la laguna narrados en el Manuscrito de Huarochiri ${ }^{86}$; las del dios con apariencia pobre -es el caso de Cuniraya Viracocha-presentes también en el Manuscrito de Huarochiri y en la tradición oral ${ }^{87}$; las uniones entre seres de arriba y de abajo, así como las historias de la tradición oral relativas a seres que habitan en los manantiales y lagunas y que a veces reciben el nombre de sirinus, Sereno o Serena: este ser existe previamente a la importación del nombre occidental, y éste se le adjudica por su coincidencia con rasgos de la Sirena europea ${ }^{88}$.

En este mito sincrético se sitúa el hilo narrativo de El Pez de Oro, pero la interpretación de esta historia tiene diferentes niveles, a través del núcleo de significado del advenimiento del Pez de Oro, el Hijo: histórico-reivindicativo, existencial y creativo. En el primero de ellos el Pez de Oro, en tanto que sucesor del Puma de Oro, su padre, sugiere una continuidad de la dinastía inca o más bien una restauración y una regeneración que apuntan a un contenido reivindicativo del mito, paralelo al del mito de Inkarri ${ }^{89}$. En el segundo, el Pez de Oro aparece relacionado con la reflexión existencial del relato, en la que esta figura, en su cualidad de hijo, representa la continuidad de la cadena vital y la posibilidad de la permanencia en la materia ligada al pensamiento animista andino, estudiado ${ }^{90}$ a propósito de otro capítulo. En tercer lugar, el Pez de Oro se relaciona con la expresión y la creación, pues la dificultad de crear una escritura andina relacionada con las lenguas nativas y los contenidos andinos se presenta desde el punto de vista de la conexión con la raíz del canto, representada por el Pez de Oro y su «trino» primordial, y por una serie de personajes míticos ligados a las cavernas y a lo acuático ${ }^{91}$.

No sólo las figuras míticas y la cosmovisión andina estructuran buena parte del sentido del libro, sino que también están presentes los sujetos del conocimiento andinos al lado de los occidentales: el Runa-hake, el PakoAchachila, el Kolliri, el Auki, el Layka, que proponen sabidurías alternativas y fundamentales frente a la simple información. También en los modos de conocimiento se combinan lo escrito andino y no andino, que en lo occidental incluye entre muchos pensadores y místicos a Kierkegaard, Goethe, Kempis, Nicolás de Cusa, Eckardt, Rousseau, Nietzsche, Schopenhauer...; al Cristo de la tradición esotérica, a la filosofía oriental; por otro lado, lo no escrito: los mitos y la adivinación; la coca como ofrenda, visión, curación y profecía; el valor iniciático de los sueños... El paralelismo del Layka con Cristo es un ejemplo de la confluencia de las tradiciones que no lleva a una adopción de modelos foráneos, sino a que ellos propicien la revelación: «iAtrévete a ser tú mismo!»92. La idea andina de la conexión con el universo, de la unión con el cosmos, le hace citar a Goethe: «Naturaleza es todo en uno» ${ }^{93}$ y religar este concepto con la dimensión filosófica del romanticismo alemán; el runa-hake, según Churata, ha asimilado a Nietzsche avant la lettre "y cultiva otra fe que «la fe en la tierra», y, lo que es más importante, la fe de la tierra; que esa fe es conciencia de la posesión de la vida» ${ }^{94}$.

Los conceptos andinos guían a menudo la exploración en los diferentes estratos temáticos, como cuando apela a la distinción entre naya (alma colectiva, pero susceptible de individuarse) у abayn (alma de la tierra), o ballpakamaska, tierra animada. Por eso, para Churata, la exploración en cierto conocimiento andino representa trazar múltiples 
y paradójicas relaciones con el conocimiento occidental y hasta con el oriental, pero también es un modo de situar a este conocimiento en otras dimensiones. Volver a la célula, al pasado genésico, es un modo de resistencia, y es también un modo de creatividad, pues en el lugar del origen, en la caverna, ocurren las revelaciones; la caverna, en la chinkana, es el fundamento: no un espacio de refugio, sino uno de regeneración, adonde se vuelve para luego emprender mejor la aventura espacial de articular los espacios exteriores. El Pez de Oro representa así lo genésico, la memoria atávica, la raíz casi inconsciente manifestada en el lenguaje como ordenador del mundo, en la percepción que hace sentido. Pero este mundo, como se ve en la figura de la célulacosmos, no es tampoco un universo cerrado, porque Churata es partidario de sustratos e intercambios, no de la cerrazón.
Éste sería, parece, el camino para desentrañar el papel de las diferentes referencias culturales en el texto de Churata: ni tomarlas como una imposible síntesis ya hecha y bendecida en el texto, ni considerarlas individualmente como definitorias de los diferentes universos culturales, sino estudiar su precaria y contradictoria relación con los universos a los que pertenecen y su interrelación en el texto. Este intento de lectura que tiene como guía la confluencia de tradiciones en El pez de oro no agota la riqueza de la obra, que se presenta como extraordinariamente sugerente también desde un punto de vista literario, tal como muestran las últimas lecturas que ponen de relieve lo subversivo y productivo del texto en tanto que obra de la tradición literaria peruana ${ }^{95}$.
Véase por ejemplo Reynaldo Jiménez, "Verás que no lo ensartas tan fácilmente», Mar con soroche, Santiago de Chile-La Paz, 2, (2006). 